\title{
Method validation for determination of 13 elements in honey samples by ICP-MS
}

\author{
Maria Chudzinska $\cdot$ Anna Debska $\cdot$ \\ Danuta Baralkiewicz
}

Received: 2 February 2011 / Accepted: 6 July 2011 / Published online: 27 September 2011

(C) The Author(s) 2011. This article is published with open access at Springerlink.com

\begin{abstract}
A method for simultaneous ICP-MS determination of 13 elements in three types of honey from Poland is described. The method was validated, and the uncertainty budget was set up. The results obtained for the relative expanded uncertainties $U_{\text {rel }}(k=2)$ were $15.1 \%$ for $\mathrm{Al}, 18.6 \%$ for $\mathrm{B}, 18.8 \%$ for $\mathrm{Ba}, 7.9 \%$ for $\mathrm{Ca}, 24.4 \%$ for $\mathrm{Cd}, 7.24 \%$ for $\mathrm{Cu}, 7.9 \%$ for $\mathrm{K}, 4.8 \%$ for $\mathrm{Mg}, 8.3 \%$ for $\mathrm{Mn}$, $12.7 \%$ for $\mathrm{Na}, 14.9 \%$ for $\mathrm{Ni}, 12.5 \%$ for $\mathrm{Pb}$ and $13.4 \%$ for $\mathrm{Zn}$. Traceability of the measurement results was established based on the use of the corn flour CRM INCT-CF-3 and the apple leaves CRM SRM 1515 and by analyzing spiked samples. Recovery rates between $94 \%(\mathrm{Zn})$ and $107 \%(\mathrm{Na})$ were found. The detection limits of all elements studied showed the suitability of the procedure for routine analyses. Summarizing it can be concluded that the described analytical procedures to measure the mass fractions of 13 elements in honey samples with established traceability and evaluated uncertainty allow to obtain reliable and internationally comparable results.
\end{abstract}

Keywords Honey $\cdot$ Multielement analysis - ICP-MS · Traceability · Uncertainty · Validation parameters

\section{Introduction}

Honey is a complex matrix, which besides sugar and water contains a great variety of components, organic as well as inorganic. The composition of honey is influenced by many

M. Chudzinska · A. Debska · D. Baralkiewicz $(\bowtie)$

Department of Trace Elements Analysis by Spectroscopy

Methods, Faculty of Chemistry, Adam Mickiewicz University,

Grunwaldzka 6, 60-780 Poznań, Poland

e-mail: danutaba@amu.edu.pl factors related to the geographical and botanical origin. The content of mineral components in honey may represent the availability of elements in the soil and plants in the area where the honey was gathered $[1,2]$. The content of these elements can provide essential information for consumers, which is why the estimation of quality parameters is so important. In recent years, concentration patterns of trace elements were widely used in food authenticity studies [1-6]. Because Poland produces many types of unifloral, multifloral and honeydew honey that are commercially available, we developed and applied analytical methods to measure the content of 13 major and trace elements in honey.

Quality of measurements plays a very important role in many fields of our life, for instance in medicine, food analysis, environmental studies or in the exchange of goods and services. Analytical chemistry aspires to obtain the most reliable analytical results, which must reflect unambiguous, true and clear values of the sample composition and to this end applies sophisticated instrumental techniques.

Establishing traceability of the measurement results of trace elements in honey is complicated by the absence of matching reference materials, despite the performed study of two honeys (Robinia and Eucalyptus) as candidates for trace elements CRM (Certified Reference Materials) [7]. Among commercially available CRM, one hardly finds an equivalent of the complex honey matrix, in particular with regard to high carbohydrate content. Hence, in many research areas, other CRM like apple leaves (SRM 1515) [3, 8-12], brown bread (BCR 191) [7], or corn (NBS 8413) $[4,5]$ are commonly applied. Due to the lack of matching CRM, other procedures are used, for instance various preparations of samples [3, 8] or applying different experimental techniques $[13,14]$. For the same purpose, in 
quality control, recovery rates are measured using spiked samples [3, 8, 9, 15-17].

The aim of this study was to validate the analytical method for quantitative determination of 13 elements in honey using the technique of inductively coupled plasma mass spectrometry, ICP-MS. Three types of honey were investigated: honeydew, buckwheat and rape. The method was fully validated according to the international guidelines ISO/IEC 17025:2005 [18], concerning (1) the parameters of the analytical procedure; (2) the uncertainty budget of the measurement; and (3) establishing traceability.

\section{Experimental}

Instruments and apparatus

For the sample pretreatment-a digestion procedure-a microwave oven was used (MARS 5, CEM). Instrumental parameters and settings are reported in Table 1 . We used an ELAN DRC II ICP-MS instrument (Perkin Elmer SCIEX, Canada) for measuring the mass fractions of all elements studied. Typical daily instrumental parameters are given in Table 2. All measurements were performed in a standard mode, although this instrument can be used in the 'dynamic reaction cell' (DRC) mode to remove polyatomic interferences.

\section{Reagents and solution}

All solutions were prepared with double deionized water obtained by passing distilled water through a Millipore Milli-Q water purification system (Waters Corporation, Milford, MA, USA). All reagents were of analytical grade unless otherwise stated. The elements standard solutions were prepared by volumetrically diluting the standard solution CertiPUR ${ }^{\circledR}$ of $\mathrm{Al}, \mathrm{B}, \mathrm{Ba}, \mathrm{Ca}, \mathrm{Cd}, \mathrm{Cu}, \mathrm{K}, \mathrm{Mg}, \mathrm{Mn}$, $\mathrm{Na}, \mathrm{Ni}, \mathrm{Pb}$ and $\mathrm{Zn}$ at $1000 \mathrm{mg} \mathrm{L}^{-1}$ (Merck, Darmstadt, Germany). The same procedure was applied to prepare a mixed solution of $\mathrm{Sc}, \mathrm{Y}$ and $\mathrm{Tb}\left(10 \mu \mathrm{g} \mathrm{L}^{-1}\right)$, which was chosen as an internal standard. Honey samples were digested with concentrated nitric acid $(65 \%$ volume concentration of $\mathrm{HNO}_{3}$ suprapur, Merck, Germany) and

Table 1 Operating conditions for the microwave oven digestion

\begin{tabular}{llllll}
\hline $\begin{array}{l}\text { Step } \\
(\mathrm{W})\end{array}$ & $\begin{array}{l}\text { Power } \\
(\mathrm{MPa})\end{array}$ & $\begin{array}{l}\text { Temperature } \\
\left({ }^{\circ} \mathrm{C}\right)\end{array}$ & $\begin{array}{l}\text { Ramp } \\
\text { time } \\
(\mathrm{min})\end{array}$ & $\begin{array}{l}\text { Hold } \\
\text { time } \\
(\mathrm{min})\end{array}$ \\
\hline 1 & 600 & 1.38 & 120 & 20 & 5 \\
2 & 600 & 1.72 & 170 & 15 & 5 \\
3 & Cooling 0 W, 15 min & & & & \\
\hline
\end{tabular}

Table 2 ICP-MS operating conditions

\begin{tabular}{ll}
\hline Spectrometer & $\begin{array}{l}\text { ELAN DRC II } \\
\text { (Perkin Elmer Sciex, } \\
\text { Canada) }\end{array}$ \\
\hline Spray chamber & Cyclonic \\
Nebulizer & Meinhard \\
Interface & Pt cones \\
Mass analizator & Quadrupole \\
RF power (W) & 1,200 \\
Ar gas flow rates $\left(\mathrm{L} \mathrm{min}^{-1}\right)$ & \\
Plasma & 15 \\
Auxiliary & 1.2 \\
Nebulizer & 0.94 \\
Lens voltage (V) & 7.75 \\
Scanning mode & $\mathrm{Peak} \mathrm{hopping}$ \\
Resolution (amu) & 0.7 \\
Replicate time (s) & 1 \\
Dwell time (ms) & 50 \\
Sweeps & 20 \\
Reading & 1 \\
Number of Replicates & 3 \\
Internal standard & $\mathrm{Sc}^{45}, \mathrm{Y}^{89}, \mathrm{~Tb}^{159}$ \\
Isotopes & $\mathrm{Al}^{27}, \mathrm{~B}^{11}, \mathrm{Ba}^{138}, \mathrm{Ca}^{43}, \mathrm{Cd}^{111}$, \\
& $\mathrm{Cu}^{63}, \mathrm{~K}^{39}, \mathrm{Mg}^{24}, \mathrm{Mn}^{55}, \mathrm{Na}^{23}$, \\
& \\
\hline & $\mathrm{Zn}^{66}$ \\
\hline
\end{tabular}

Corrected intensities $I_{\text {corr }}$ :

$I_{\text {corr }}\left(\mathrm{Ba}^{138}\right)=I\left(\mathrm{Ba}^{138}\right)-0.000901 I\left(\mathrm{La}^{139}\right)-0.002838 I\left(\mathrm{Ce}^{140}\right)$,

$I_{\text {corr }}\left(\mathrm{Mn}^{55}\right)=I\left(\mathrm{Mn}^{55}\right)-0.00014 I\left(\mathrm{Cl}^{35}\right)$,

$I_{\text {corr }}\left(\mathrm{Ni}^{60}\right)=I\left(\mathrm{Ni}^{60}\right)-0.0022 I\left(\mathrm{Ca}^{44}\right)$

hydrogen peroxide (30\% volume concentration of $\mathrm{H}_{2} \mathrm{O}_{2}$ pure p.a, Chempur, Poland). A recovery test was performed using a spike solution and two References Materials, namely CRM corn flour INCT-CF-3 (ICHTJ, Poland) and Standard Reference Material (SRM) apple leaves (SRM 1515, NIST National Institute of Standards and Technology, Gaithersburg, USA). Spike solutions were prepared from stock solutions as a multielement solution. A volume of $1 \mathrm{~mL}$ of spike solution comprises $1000 \mathrm{mg} \mathrm{kg}^{-1} \mathrm{~K}$; $100 \mathrm{mg} \mathrm{kg}^{-1} \mathrm{Ca}$ and $\mathrm{Mg}$; $10 \mathrm{mg} \mathrm{kg}^{-1} \mathrm{Al}, \mathrm{Zn}, \mathrm{Mn}, \mathrm{Cu}$; and $1 \mathrm{mg} \mathrm{kg}^{-1} \mathrm{~B}, \mathrm{Ni}, \mathrm{Cd}, \mathrm{Ba}, \mathrm{Pb}$. With regard to sample preparation, spiking them with the multielement solution proved to be most successful and was preferred over single element solutions.

Honey samples

The procedure was validated on honey samples which consisted of three types of honey: honeydew, buckwheat and rape honey, which came from different areas in Poland. All samples were unpasteurized and collected from the local association of beekeepers with a guaranteed origin 
and prepared by applying traditional procedures of the honey-producing region. The samples were stored in glass bottles and kept at $4-5{ }^{\circ} \mathrm{C}$ in dark place until analysis $[1,2]$.

\section{Analytical procedure}

\section{Sample preparation}

Honey samples were digested using a microwave oven decomposition system (Mars 5, CEM) according to the following procedure. Aliquots of approximately $1 \mathrm{~g}$ of each honey sample were accurately weighed in a PFA digestion vessel, and then, $9 \mathrm{~mL}$ of $65 \%$ volume concentration nitric acid and $1 \mathrm{~mL}$ of $30 \%$ volume concentration $\mathrm{H}_{2} \mathrm{O}_{2}$ were added. The bomb was placed inside the microwave oven, and the decomposition was carried out according to the program shown in Table 1. After that, the digests were left to cool, and then, the volume was made up to $50 \mathrm{~mL}$ with Milli-Q water. Blank solutions and CRM samples were prepared in the same way. The average signal of blank solutions was subtracted from analytical signals of honey samples. The analytical quality control (analytical procedure validation, uncertainty and traceability) was verified using the CRM corn flour INCT-CF-3 and SRM apple leaves SRM 1515. The obtained results are presented in Table 5. Thirteen elements (Al, B, Ba, Ca, Cd, $\mathrm{Cu}, \mathrm{K}, \mathrm{Mg}, \mathrm{Mn}, \mathrm{Na}, \mathrm{Ni}, \mathrm{Pb}, \mathrm{Zn}$ ) were determined in honey sample.

\section{Calibration procedure}

Calibration curves were build on 5-7 different mass concentrations. Standard solutions were prepared by diluting a multielement solution of $\mathrm{Sc}, \mathrm{Y}$, and $\mathrm{Tb}\left(10 \mu \mathrm{g} \mathrm{mL}^{-1}\right)$ and a multielement solution of $\mathrm{Al}, \mathrm{B}, \mathrm{Ba}, \mathrm{Ca}, \mathrm{Cd}, \mathrm{Cu}, \mathrm{K}, \mathrm{Mg}$, $\mathrm{Mn}, \mathrm{Na}, \mathrm{Ni}, \mathrm{Pb}$ and $\mathrm{Zn}$. The mass concentration range for the elements Sc, Y and Tb was $0.01-100 \mu \mathrm{g} \mathrm{L}^{-1}$, whereas the mass concentration range for the elements $\mathrm{Ba}, \mathrm{Cd}, \mathrm{Cr}$, $\mathrm{Mn}, \mathrm{Ni}, \mathrm{Pb}$ and $\mathrm{Zn}$ was $0.05-50 \mu \mathrm{g} \mathrm{L}^{-1}$; for $\mathrm{Al}$ and $\mathrm{Cu}$, 0.05-200 $\mu \mathrm{g} \mathrm{L}^{-1}$; for $\mathrm{B}, 0.05-400 \mu \mathrm{g} \mathrm{L}^{-1}$; and for $\mathrm{Ca}, \mathrm{K}$, $\mathrm{Mg}$, Na 5-5000 $\mu \mathrm{g} \mathrm{L}^{-1}$.

\section{Results and discussion}

A detailed validation of the analytical procedure for determining major and trace elements in honey samples was conducted. The validation included the performance parameters selectivity and specificity, linearity, limit of detection $(L O D)$ and limit of quantification $(L O Q)$; precision, accuracy and an uncertainty budget.
Selectivity and specificity

Specificity depends on the selected element and possible interferences. The various types of spectral interferences concerning matrix effects, drift, stability and the factors that influence the stability encountered using ICP-MS were explored. ICP-MS as a technique suffers from unwanted spectral and non-spectral interferences, which might adulterate the analyzed elemental composition of the samples. The high concentration of organic matrix often results in matrix interferences and/or spectral interferences from polyatomic ions. These effects may be eliminated or at least minimized by the use of alternative isotopes and/or interference correction equations. Also in our work corrections, equations were applied in order to minimize isobaric interferences from matrix. The possibilities to reduce or even eliminate interferences were explored; in particular, appropriate isotopes were selected (Table 2). The primary isotopes for each element were used. Dissolution allowed to decrease acidification of samples and matrix effects connected with viscosity.

\section{Range of linearity and calibration curve}

The ICP-MS analysis was calibrated using external standards to increase the sample throughput. Although ICP-MS is well known for a wide working range of mass concentrations from ng $\mathrm{L}^{-1}$ to $\mathrm{mg} \mathrm{L}^{-1}$ level in a single analysis, its parameters were evaluated by checking the linear regression coefficient of the calibration curves based on measurement results from 5 to 7 standards. Linearity was considered satisfactory if the correlation coefficient $r$ exceeded 0.999 [19], and actually we found $r=0.9996$ for $\mathrm{Cd}, 0.9997$ for $\mathrm{K}$ and to 0.9999 for the rest of the elements studied. The calibration curves for $\mathrm{Al}, \mathrm{B}, \mathrm{Ba}, \mathrm{Cd}$, $\mathrm{Cu}, \mathrm{Mn}, \mathrm{Ni}, \mathrm{Pb}$ and $\mathrm{Zn}$ were linear in the range between 0.05 and $200 \mu \mathrm{g} \mathrm{L}^{-1}$ and for $\mathrm{K}, \mathrm{Ca}, \mathrm{Mg}$ and Na between 5 and $5000 \mu \mathrm{g} \mathrm{L}^{-1}$. In most cases, the linear interval was fully covered by the working range of ICP-MS [20]. For each element, the equation of the linear calibration curve was evaluated (Table 3). Similar values of the correlation coefficient were reported by Terrab et al. [20] who used ICP-OES.

Limits of detection and limits of quantification

These limits were estimated from the analysis of blank samples. The procedure detection limits $(L O D)$ were calculated as three times the standard deviation $(s)$ of the signal from reagent blanks, and the limits of quantification $(L O Q)$ as $10 \mathrm{~s}$. The standard deviation $s$ was derived from 10 measurements of independently prepared blank reagent solutions. $L O D$ obtained for mass fractions of elements 
Table 3 Results of determination of analytical procedure parameters

\begin{tabular}{|c|c|c|c|c|c|c|}
\hline \multirow[t]{3}{*}{ Element } & \multicolumn{6}{|c|}{ Validation parameters of the analytical procedure } \\
\hline & \multirow{2}{*}{$\begin{array}{l}\text { Linear equation } \\
x, y\left(\mu \mathrm{g} \mathrm{L}^{-1}\right)\end{array}$} & \multirow{2}{*}{$\begin{array}{l}\text { Range of } \\
\text { linearity }\left(\mathrm{mg} \mathrm{kg}^{-1}\right)\end{array}$} & \multirow{2}{*}{$\begin{array}{l}L O D \\
\left(\mathrm{mg} \mathrm{kg}^{-1}\right)\end{array}$} & \multirow{2}{*}{$\begin{array}{l}L O Q \\
\left(\mathrm{mg} \mathrm{kg}^{-1}\right)\end{array}$} & \multicolumn{2}{|l|}{ Precision $(\mathrm{CV})$} \\
\hline & & & & & Repeatability (\%) & $\begin{array}{l}\text { Within-laboratory } \\
\text { reproducibility }(\%)\end{array}$ \\
\hline $\mathrm{Al}$ & $y=0.0063 x+0.0053$ & $2.5-54$ & 0.94 & 3.12 & 2.43 & 3.68 \\
\hline $\mathrm{B}$ & $y=0.0003 x+0.0011$ & $1.75-14$ & 0.53 & 1.76 & 1.75 & 7.15 \\
\hline $\mathrm{Ba}$ & $y=0.0256 x+0.0013$ & $0.2-0.8$ & 0.16 & 0.40 & 3.88 & 4.31 \\
\hline $\mathrm{Ca}$ & $y=0.00004 x+0.018$ & $12.5-130$ & 3.95 & 12.84 & 1.72 & 5.85 \\
\hline $\mathrm{Cd}$ & $y=0.0026 x+0.0003$ & $0.0125-0.06$ & 0.004 & 0.01 & 2.32 & 7.71 \\
\hline $\mathrm{Cu}$ & $y=0.0207 x+0.0002$ & $0.35-2.5$ & 0.11 & 0.36 & 2.81 & 9.26 \\
\hline $\mathrm{K}$ & $y=0.0098 x+0.5374$ & $25-3700$ & 7.5 & 26.66 & 1.65 & 8.33 \\
\hline $\mathrm{Mg}$ & $y=0.0029 x+0.0232$ & $10.5-65$ & 3.19 & 10.65 & 1.62 & 3.55 \\
\hline $\mathrm{Mn}$ & $y=0.0185 x+0.0014$ & $0.25-16$ & 0.08 & 0.27 & 3.32 & 5.85 \\
\hline $\mathrm{Na}$ & $y=0.0052 x+0.5627$ & $17.0-95$ & 5.09 & 16.95 & 1.85 & 3.56 \\
\hline $\mathrm{Ni}$ & $y=0.0161 x+0.0041$ & $0.125-1.5$ & 0.034 & 0.11 & 1.59 & 3.87 \\
\hline $\mathrm{Pb}$ & $y=0.1364 x+0.0123$ & $0.05-1.7$ & 0.02 & 0.07 & 1.09 & 10.57 \\
\hline $\mathrm{Zn}$ & $y=0.0037 x+0.0011$ & $0.75-6.8$ & 0.22 & 0.74 & 2.67 & 2.90 \\
\hline
\end{tabular}

ranged from $0.004 \mathrm{mg} \mathrm{kg}^{-1}$ for $\mathrm{Cd}$ to $7.5 \mathrm{mg} \mathrm{kg}^{-1}$ for $\mathrm{K}$, and consequently, the limits of quantification $(L O Q)$ ranged from $0.01 \mathrm{mg} \mathrm{kg}^{-1}$ for $\mathrm{Cd}$ to $26.66 \mathrm{mg} \mathrm{kg}^{-1}$ for $\mathrm{K}$; a complete list is given in Table 3. When compared to a study using GFAAS [8], the simultaneous procedure proposed here offers better detection limits and similar or even better precision.

Precision (repeatability and within-laboratory reproducibility)

Repeatability (single laboratory precision) can initially be based upon one homogeneous sample. The precision was evaluated using relative standard deviation of replicated measurements (one sample was analyzed 10 times). Intraday variation coefficients ( $C V$ for one sample preparation, 10 measurements of the same sample) were in the range of $1.09-3.88 \%$. The within-laboratory reproducibility ( $C V$ for 10 different sample preparations, 10 measurements on different days) did not exceed $15 \%(N=10)$ for all analytes. These values fulfilled our required criteria that repeatability should be less than 5\% and within-laboratory reproducibility less than $15 \%$.

\section{Uncertainty budget}

The assessment of uncertainty permits comparison between or within laboratories and with respect to reference values. Moreover, it helps to demonstrate traceability. Several approaches have been described for the evaluation of uncertainty. Among these, the "bottom-up" approaches of the Guide to the Expression of Uncertainty in Measurement
(GUM) [21] are based on the identification and estimation of all the sources of uncertainty in the analytical process (based on intralaboratory data). This approach quantifies the uncertainty associated with individual effects and analytical steps that cause random and systematic errors of the measurements. Alternatively, the "top-down" approaches based on in-house validation data used either repeatability or intralaboratory reproducibility data. The data collected during the in-house validation of an analytical method should allow to identify relevant sources of uncertainty and their influence. With a bottom-up approach, the influence of individual factors and the corresponding uncertainties can be determined separately in a single experiment with optimum use of the generated data, in this way achieving a favorable ratio between the costs and the results, while the "top-down" approach is based on interlaboratory data (interlaboratory comparison, ILC; proficiency test, PT). The dispersion of results from such a test is used to estimate the uncertainty associated with measurements taken within a laboratory. Uncertainty estimation is based on precision and trueness of data [22]. Also, a combination of the different approaches very often needs to be used to assess the uncertainty [23].

In our study, the measurement uncertainty of the method was estimated following a GUM "bottom-up approach" $[21,24,25]$ that is adopted by most practitioners. In this approach, the measurement process is modeled starting from the input quantities, each made up from an estimate (value) and its associated standard uncertainty. The values and the associated uncertainties are 'propagated' through the model to provide an estimate of the output quantity and its associated standard uncertainty. Among others, these 


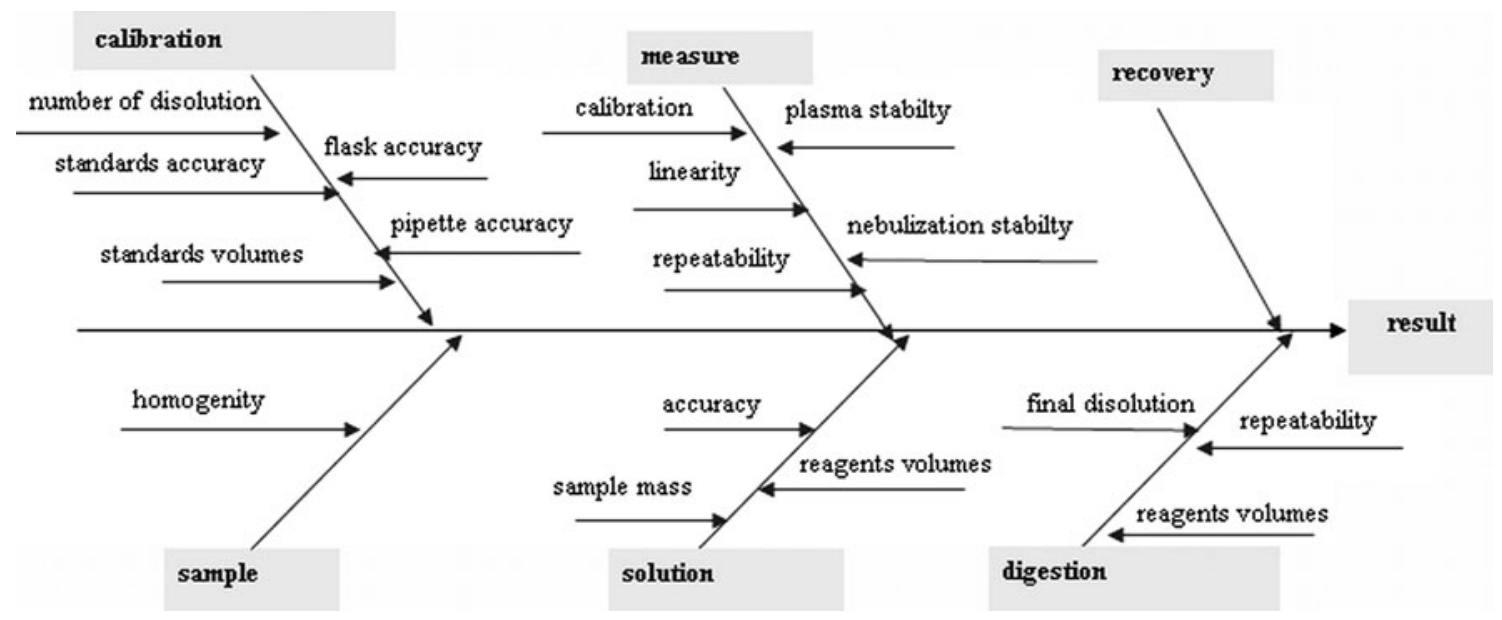

Fig. 1 Ishikawa diagram for the procedure of determination of 13 elements using ICP-MS

principles require that uncertainty evaluation is comprehensive, accounting for all relevant sources of measurement error; statistical evaluation of measurements (Type A) and alternative techniques, based on other data and information (Type B), are recognized and utilized as equally valid tools; the uncertainties of the final results are expressed as standard deviations (standard uncertainty) or by multiples of standard deviations (expanded uncertainty) with a specified numerical factor (coverage factor). The GUM is based on sound theory and provides a consistent and transferable evaluation of measurement uncertainty. Modeling the measuring process is particularly useful for evaluating the contribution of reference value uncertainties to the combined uncertainty associated with the final measurement result. These approaches are based on long experience and reflect common practice [23].

In the first step, the measurement function is established to describe the relationship between the output quantity and the input quantities, i.e., measurement results:

$w=\frac{\gamma \cdot V_{s}}{m_{s}} \cdot f_{d}$

where $w$ denotes the mass fraction of an analyte in a sample $\left(\mathrm{mg} \mathrm{kg}^{-1}\right), \gamma$ the analyte mass concentration in a solution $\left(\mathrm{mg} \mathrm{L}^{-1}\right), V_{s}$ the sample volume $(\mathrm{mL}), m_{s}$ the sample mass $(\mathrm{g})$, and $f_{d}$ the dilution coefficient.

The quantities having an influence on the uncertainty of the measurement result are arranged in a so-called fishbone diagram as shown in Fig. 1. Not all sources could be identified; however, we focused on those providing the largest contributions to the final result. Among these are recovery, calibration, preparation of the standard solutions and the sample mass, and we applied Type A and B evaluation as appropriate. Type B evaluation was necessary, e.g., where producer information referred to tolerances (e.g., concerning balance) [19, 21, 24, 25]. Evaluated uncertainty values are presented in Table 4.

The standard uncertainty of calibration, $u(\mathrm{cal}$.), is an important component of the combined uncertainty. Its values were calculated using the previously evaluated relative uncertainty of the mass concentration of the standard solution $u\left(\gamma_{s t d}\right) / \gamma_{s t d}$, the volumes of the pipettes $\left(V_{p}\right)$ and the flask $\left(V_{f}\right)$ used for preparation of the particular standard solution. The relative concentration uncertainty of the multielement standard solution was calculated as a relative uncertainty of the preparation of individual calibration solutions including the dilution coefficient. The repeatability of the concentration measurements was taken into consideration as the relative standard deviation $R S D_{\text {meas }}^{\text {std }}$ of 3 measurements $(n)$ of each standard solution.

$u($ cal. $)=$

$\sqrt{\left(\frac{u\left(\gamma_{\text {std }}\right)}{\gamma_{\text {std }}}\right)^{2}+\sum_{i=1}^{z}\left(\frac{u\left(V_{p}\right)}{V_{p}}\right)^{2}+\sum_{i=1}^{z}\left(\frac{u\left(V_{f}\right)}{V_{f}}\right)^{2}+\sum_{i=1}^{z}\left(\frac{R S D_{\text {meas }}^{\text {std }}}{\sqrt{n}}\right)^{2}}$

where $u(\mathrm{cal}$.) denotes the standard uncertainty for calibration, $\gamma_{s t d}$ the mass concentration of the working standard solution $\left(\mathrm{mg} \mathrm{L}^{-1}\right), u\left(\gamma_{s t d}\right)$ its standard uncertainty, $z$ the number of dilutions, $V_{p}$ the volume of the pipettes $(\mathrm{mL})$, and $V_{f}$ the volume of the flask $(\mathrm{mL})$.

The standard uncertainties related to the repeatability of the digestion and for the one of the ICP-MS measurements were evaluated. The RSD of the results of 10 replicated measurements of one honey samples or, in case of digestion, of independently prepared honey samples was considered as repeatability uncertainty. The next component in the estimation of the uncertainty is the standard uncertainty of the recovery rate, which was 
Table 4 Evaluation of relative standard uncertainty, combined standard uncertainty and expanded uncertainty for 13 elements mass fraction in honey samples

\begin{tabular}{|c|c|c|c|c|c|c|c|c|c|}
\hline Element & $u\left(m_{s}\right) / m_{s}$ & $u\left(V_{s}\right) / V_{s}$ & $u($ cal. $)$ & $u(R)$ & $u\left(r_{d}\right)$ & $u\left(r_{m}\right)$ & $u_{c}(w) / w$ & $U_{\mathrm{rel}}(k=2)(\%)$ & $w \pm U\left(\mathrm{mg} \mathrm{kg}^{-1}\right)$ \\
\hline $\mathrm{Al}$ & 0.00008 & 0.00086 & 0.011 & 0.028 & 0.069 & 0.008 & 0.075 & 15.1 & $10.50 \pm 1.58$ \\
\hline B & & & 0.013 & 0.089 & 0.023 & 0.006 & 0.092 & 18.6 & $6.92 \pm 1.29$ \\
\hline $\mathrm{Ba}$ & & & 0.013 & 0.051 & 0.078 & 0.013 & 0.094 & 18.8 & $0.12 \pm 0.02$ \\
\hline $\mathrm{Ca}$ & & & 0.018 & 0.00009 & 0.034 & 0.006 & 0.039 & 7.9 & $44.40 \pm 3.50$ \\
\hline $\mathrm{Cd}$ & & & 0.012 & 0.118 & 0.026 & 0.024 & 0.121 & 24.4 & $0.021 \pm 0.005$ \\
\hline $\mathrm{Cu}$ & & & 0.012 & 0.025 & 0.021 & 0.009 & 0.036 & 7.2 & $0.82 \pm 0.06$ \\
\hline $\mathrm{K}$ & & & 0.038 & 0.0004 & 0.004 & 0.005 & 0.039 & 7.9 & $1346 \pm 107$ \\
\hline $\mathrm{Mg}$ & & & 0.016 & 0.016 & 0.003 & 0.005 & 0.023 & 4.8 & $18.50 \pm 0.89$ \\
\hline Mn & & & 0.017 & 0.024 & 0.016 & 0.024 & 0.041 & 8.3 & $4.96 \pm 0.41$ \\
\hline $\mathrm{Na}$ & & & 0.017 & 0.056 & 0.008 & 0.006 & 0.063 & 12.7 & $24.80 \pm 2.97$ \\
\hline $\mathrm{Ni}$ & & & 0.018 & 0.072 & 0.005 & 0.005 & 0.074 & 14.9 & $0.42 \pm 0.06$ \\
\hline $\mathrm{Pb}$ & & & 0.012 & 0.061 & 0.005 & 0.004 & 0.062 & 12.5 & $0.43 \pm 0.05$ \\
\hline $\mathrm{Zn}$ & & & 0.016 & 0.056 & 0.030 & 0.009 & 0.066 & 13.4 & $3.22 \pm 0.43$ \\
\hline
\end{tabular}

$u\left(m_{s}\right)$, standard uncertainty for the sample mass; $u\left(V_{s}\right)$, standard uncertainty for the sample preparation; $u(c a l$.$) , standard uncertainty for the$ calibration; $u(R)$, standard uncertainty of recovery; $u\left(r_{d}\right)$, standard uncertainty for the digestion repeatability; $u\left(r_{m}\right)$, standard uncertainty for the repeatability of ICP-MS measurement; $u_{c}(w)$, combined uncertainty of mass fraction; $w$, mass fraction of the element in honey samples; $U$, expanded uncertainty $(k=2)$

Table 5 Analysis of certified reference material for elements determination

\begin{tabular}{|c|c|c|c|c|c|c|}
\hline Element & $\begin{array}{l}\text { Certified value } \\
\text { CRM INCT-CF-3 } \\
\bar{w} \pm U \\
\left(\mathrm{mg} \mathrm{kg}^{-1}\right)\end{array}$ & $\begin{array}{l}\text { Obtained value } \\
\text { INCT-CF-3 } \\
\bar{w} \pm S D \\
\left(\mathrm{mg} \mathrm{kg}^{-1}\right)\end{array}$ & $\begin{array}{l}\text { Recovery } \\
(\%)\end{array}$ & $\begin{array}{l}\text { Certified value } \\
\text { SRM1515 } \\
\bar{w} \pm U \\
\left(\mathrm{mg} \mathrm{kg}^{-1}\right)\end{array}$ & $\begin{array}{l}\text { Obtained value } \\
\text { SRM1515 } \\
\bar{w} \pm S D \\
\left(\mathrm{mg} \mathrm{kg}^{-1}\right)\end{array}$ & $\begin{array}{l}\text { Recovery } \\
(\%)\end{array}$ \\
\hline $\mathrm{A} 1^{*}$ & 12 & $11.2 \pm 0.92$ & 93.3 & $286 \pm 9$ & $301 \pm 11$ & 105 \\
\hline B & $1.65 \pm 0.33$ & $1.69 \pm 0.06$ & 102 & $27 \pm 2$ & $27 \pm 5$ & 100 \\
\hline $\mathrm{Ba}^{*}$ & 0.117 & $0.118 \pm 0.020$ & 100 & $49 \pm 2$ & $43.5 \pm 6.7$ & 88.8 \\
\hline $\mathrm{Ca}^{*}$ & 40 & $38.9 \pm 2.8$ & 97.3 & $15260 \pm 2.289$ & $15310 \pm 1.1$ & 100 \\
\hline $\mathrm{Cd}^{*}$ & 0.007 & $0.006 \pm 0.001$ & 88.6 & $0.013 \pm 0.002$ & $0.013 \pm 0.003$ & 100 \\
\hline $\mathrm{Cu}$ & $1.63 \pm 0.13$ & $1.69 \pm 0.053$ & 103 & $5.64 \pm 0.24$ & $5.81 \pm 0.12$ & 103 \\
\hline $\mathrm{K}$ & $3157 \pm 119$ & $3116 \pm 37$ & 98.7 & $16100 \pm 3.22$ & $15980 \pm 9.2$ & 99.3 \\
\hline $\mathrm{Mg}$ & $1066 \pm 37$ & $995 \pm 4.6$ & 93.3 & $2710 \pm 0.2168$ & $2670 \pm 1.7$ & 98.5 \\
\hline $\mathrm{Mn}$ & $4.98 \pm 0.22$ & $4.87 \pm 0.18$ & 97.8 & $54 \pm 3$ & $49 \pm 4.9$ & 90.7 \\
\hline $\mathrm{Na}^{*}$ & 4.4 & $4.3 \pm 0.9$ & 97.7 & $24.4 \pm 1.2$ & $26.2 \pm 2.1$ & 107 \\
\hline $\mathrm{Ni}$ & $0.383 \pm 0.039$ & $0.367 \pm 0.065$ & 95.8 & $0.91 \pm 0.12$ & $0.87 \pm 0.07$ & 95.6 \\
\hline $\mathrm{Pb}^{*}$ & 0.052 & $0.055 \pm 0.003$ & 105 & $0.470 \pm 0.024$ & $0.458 \pm 0.073$ & 97.5 \\
\hline $\mathrm{Zn}$ & $20.09 \pm 0.76$ & $19.11 \pm 1.2$ & 95.0 & $12.5 \pm 0.3$ & $11.7 \pm 1.2$ & 93.6 \\
\hline
\end{tabular}

$\bar{w}$ mean value of mass fraction of the element in $C R M$ samples, $N=7, S D$, standard deviation; $U$, expanded uncertainty $(k=2)$

* informative values for CRM INCT-CF-3

determined by using CRM (Table 5). The recovery level should be between 90 and $110 \%$ according to our requirements concerning this elaborated analytical procedure.

In a next step, we converted all the standard uncertainties into dimensionless relative standard uncertainties, and thereafter, the combined uncertainty $u_{c}(w)$ was calculated using propagation principles (Eq. 3) [19, 21, 23].

$$
\begin{aligned}
& \frac{u_{c}(w)}{w} \\
& =\sqrt{\left(\frac{u\left(m_{s}\right)}{m_{s}}\right)^{2}+\left(\frac{u\left(V_{s}\right)}{V_{s}}\right)^{2}+u(c a l .)^{2}+u(R)^{2}+u\left(r_{d}\right)^{2}+u\left(r_{m}\right)^{2}}
\end{aligned}
$$

where $w$ denotes the mass fraction of an element in the honey samples and $u_{c}(w)$ its combined uncertainty, $u\left(m_{s}\right)$ is 
the standard uncertainty of the sample mass $m_{s}, u\left(V_{s}\right)$ the standard uncertainty for the sample preparation, $u(\mathrm{cal}$.) the standard uncertainty for the calibration, $u(R)$ the standard uncertainty of recovery rate, $u\left(r_{d}\right)$ the standard uncertainty of the digestion repeatability, and $u\left(r_{m}\right)$ the standard uncertainty for the repeatability of ICP-MS measurement.

Eventually the expanded uncertainty $U$ was calculated by multiplying the combined uncertainty by the coverage factor $k$, which as usual was chosen to be $k=2$ to achieve a level of confidence of approximately $p=95 \%[19,21$, 23]. The relative expanded uncertainties $U_{\text {rel }}(k=2)$ were found to be between $4.8 \%$ for $\mathrm{Mg}$ and $24.4 \%$ for $\mathrm{Cd}$, the values for all elements are found in Table 4 .

The observed differences in $U_{\text {rel }}$ seem to correlate with the content of the elements in honey samples (major or trace element). The uncertainty we obtained for $\mathrm{Cd}$ was worse in comparison with that of other studies [26, 27]. It could be attributed to the differences between the matrices of honey, milk and lichen. Additionally, we included more factors in the uncertainty budget than was done in literature studies. Moreover, in our study, a low recovery rate for $\mathrm{Cd}$ in CRM corn flour INCT-CF-3 was obtained, so that its uncertainty contribution was considerable. The expanded uncertainty for $\mathrm{Cd}$ in lichen using the bottom-up approach according to a new guide [25] was $14.7 \%$ [26]. The expanded uncertainty for concentration of $\mathrm{Cd}$ in milk samples according to a "fitness-for-purpose" approach was $15.8 \%$, whilst for $\mathrm{Pb}$, the uncertainty of our procedure of $18.9 \%$ was better than the one reported by D'Ilio et al. [27].

In order to assess the analytical process, the contributions of the individual stages to the combined uncertainty were studied [28]. Each uncertainty contribution was expressed as the percentage of the algebraic sum of all contributions. It turned out that for different elements a given component of the uncertainty budget contributes differently to the accumulated uncertainty, what may be due to the different contents of major and trace elements and due to various reference solutions applied. However, for all analytes, we find that the uncertainty caused by sample preparation is less than $1 \%$, so that this step is of low importance.

The repeatability of the ICP-MS measurement is also no dominant contribution to the uncertainty, as it is less than $10 \%$, except for manganese (29\%), copper (14\%) and magnesium (13\%). However, the uncertainty of the calibration stage plays an important part in the budget as for most elements it exceeds 10\%. Different from other results, where the lowest uncertainty contribution comes from the recovery rate, while the highest are those of the preparation of standard solution and of repeatability [27], we found an opposite situation for $\mathrm{Pb}$ and $\mathrm{Cd}$. It is noteworthy that in our study, $u(\mathrm{cal}$.) is constitutive in the uncertainty budget for the major elements (from $28 \%$ for sodium to $78 \%$ for potassium). These high values could be caused by the different number of standard solutions and their mass fractions for the individual elements. We also notice that the next important stage of the analytical procedure is connected with sample decomposition and digestion repeatability: for elements such as $\mathrm{Al}, \mathrm{Ba}$ and $\mathrm{Ca}$, it is the decisive step.

While for the major elements, with the exception of $\mathrm{Na}$, the influence of the recovery uncertainty is almost negligible, for all trace elements, except $\mathrm{K}$ and $\mathrm{Ca}$, recovery affects the uncertainty considerably. Actually the lower the content of the other elements such as $\mathrm{Na}, \mathrm{Zn}, \mathrm{Cu}$ or $\mathrm{B}$ is, the more relevant is the recovery uncertainty. A simple explanation could be that with approximately equal absolute uncertainties, the relative uncertainties depend on the concentration of a given element in the CRM.

\section{Establishing traceability}

To achieve traceability of a measurement result, analyzing of a CRM or comparing results by two different techniques is recommended. However, no matching CRM of honey is commercially available. Caroli et al. [7] ascribed the lack of a honey CRM to difficulties with obtaining a stable homogenous material. In order to establish traceability of the results of our study, CRMs of high carbohydrate concentration and similar content of determined elements were applied, namely CRM corn flour INCT-CF-3 and SRM apple leaves SRM 1515. In addition, recovery rates from spiked samples were measured to assure the traceability of measurements within a laboratory. The Polish CRM corn flour INCT-CF-3, which was certified by an interlaboratory comparison (92 laboratories from 19 countries), and SRM apple leaves NIST-1515 as Primary Reference Material, permitted us to establish the traceability to SI. Also the traceability was evaluated by determining recoveries of the analytes by the application of spiked honey solutions. In Table 5, the measured mass fractions (average of 7 results and their standard deviation) were compared with the certified mass fractions of the control materials. The low values prove good repeatability of the procedure.

The limits of the target values were set by the supplier of the control material. The comparison of target values with measured values shows sufficient agreement for all elements, without obvious outliers. No significant statistical differences at $95 \%$ confidence level were observed between certified values and found levels for CRM analyses by applying paired $t$-test. The recoveries obtained show acceptable results $(90-110 \%)$ for all analyzed element, except for Cd in CRM corn flour INCT-CF-3 and for Ba in SRM apple leaves SRM 1515. These values, however, are close to $90 \%$, and they could be accounted for the elements whose values are provided informative, but are not certified. 
Table 6 Recovery of elements from spiked honey samples, $N=7$

\begin{tabular}{lllll}
\hline Element & $\begin{array}{l}\text { Added } \\
\left(\mathrm{mg} \mathrm{kg}^{-1}\right)\end{array}$ & \multicolumn{2}{l}{ Measured mass fractions } & $\begin{array}{l}\text { Recovery } \\
(\%)\end{array}$ \\
\cline { 3 - 4 } & & $\begin{array}{l}\text { Honey samples } \\
\left(\mathrm{mg} \mathrm{kg}^{-1}\right)\end{array}$ & $\begin{array}{l}\text { Spiked samples } \\
\left(\mathrm{mg} \mathrm{kg}^{-1}\right)\end{array}$ & \\
\hline $\mathrm{Al}$ & 10.0 & 2.96 & 12.50 & 95.4 \\
$\mathrm{~B}$ & 1.0 & 11.85 & 12.76 & 91.0 \\
$\mathrm{Ba}$ & 1.0 & 0.18 & 1.17 & 99.1 \\
$\mathrm{Ca}$ & 100.0 & 78.0 & 174.0 & 96.0 \\
$\mathrm{Cd}$ & 1.0 & 0.024 & 1.022 & 99.8 \\
$\mathrm{Cu}$ & 10.0 & 1.31 & 11.29 & 99.8 \\
$\mathrm{~K}$ & 1000.0 & 995.0 & 1989.0 & 99.4 \\
$\mathrm{Mg}$ & 100.0 & 30.0 & 128.0 & 98.0 \\
$\mathrm{Mn}$ & 10.0 & 6.50 & 16.40 & 99.0 \\
$\mathrm{Ni}$ & 1.0 & 0.84 & 1.79 & 95.0 \\
$\mathrm{~Pb}$ & 1.0 & 0.59 & 1.58 & 99.0 \\
$\mathrm{Zn}$ & 10.0 & 3.27 & 12.82 & 95.5 \\
\hline
\end{tabular}

The good agreement between found values and certified values indicates effective recovery of analytes after digestion. Our recovery values for $\mathrm{Cu}, \mathrm{Mn}$ and $\mathrm{Zn}$ are similar to those obtained by Tuzen and Soylak [15], with the exception of $\mathrm{Pb}$ and $\mathrm{Cd}$ which are better in our study. Also our values are comparable with those obtained by Salomon et al. [29]; however, our results for $\mathrm{Cd}$ and $\mathrm{Cu}$ are better. The recovery rates measured for $\mathrm{Cd}, \mathrm{Al}, \mathrm{K}$ and $\mathrm{Ca}$ are definitely higher than those obtained by Sillici et al. [9], while those for $\mathrm{Zn}$ are much lower in our research; for the rest of the elements $(\mathrm{Cu}, \mathrm{Pb}, \mathrm{Cr}$ and $\mathrm{Ni})$, the results are similar. Also Conti and Botre [12] reported similar values to those in our study, except a better one for Mn.

The common technique used for proving traceability is the analysis of spiked samples (addition of a known amount of standard solution). Effectiveness of this procedure is evaluated by calculated recoveries. The technique could reveal a mistake made in sample preparation or with matrix. Spike recoveries of $1 \mathrm{mg} \mathrm{L}^{-1}$ multielement spike solution were in the range of $90-99.8 \%$. The results for this work are summarized in Table 6. The results were in acceptable range. In comparison with other reports [8], the results were better.

\section{Application of the procedure to honey samples}

In an attempt to characterize Polish honey from the point of view of their mineral content, 13 elements were quantified in 3 different kinds of honey samples. The results for three independent samples for each honey are listed in Table 7. Moreover, this analytical procedure combined with chemometric methods was applied to define the authenticity of honey origin in our previous papers $[1,2]$.
Table 7 Results of the analysis of honey samples $(N=15$; $\bar{w} \pm U(k=2))\left(\mathrm{mg} \mathrm{kg}^{-1}\right)$

\begin{tabular}{lccc}
\hline & Buckwheat honey & Rape honey & Honeydew honey \\
\hline $\mathrm{Al}$ & $2.46 \pm 0.37$ & $1.96 \pm 0.30$ & $20.13 \pm 3.04$ \\
$\mathrm{~B}$ & $5.91 \pm 1.10$ & $12.15 \pm 2.26$ & $4.90 \pm 0.91$ \\
$\mathrm{Ba}$ & $0.12 \pm 0.02$ & $0.12 \pm 0.02$ & $0.16 \pm 0.03$ \\
$\mathrm{Ca}$ & $48.22 \pm 3.81$ & $66.43 \pm 5.25$ & $40.97 \pm 3.24$ \\
$\mathrm{Cd}$ & $0.017 \pm 0.004$ & $0.020 \pm 0.005$ & $0.044 \pm 0.011$ \\
$\mathrm{Cu}$ & $1.02 \pm 0.07$ & $0.36 \pm 0.03$ & $1.31 \pm 0.09$ \\
$\mathrm{~K}$ & $820 \pm 64$ & $366 \pm 28$ & $3079 \pm 243$ \\
$\mathrm{Mg}$ & $28.45 \pm 1.37$ & $22.76 \pm 1.09$ & $59.95 \pm 2.88$ \\
$\mathrm{Mn}$ & $7.12 \pm 0.59$ & $0.71 \pm 0.06$ & $4.17 \pm 0.35$ \\
$\mathrm{Na}$ & $35.43 \pm 4.50$ & $25.63 \pm 3.26$ & $38.93 \pm 4.94$ \\
$\mathrm{Ni}$ & $0.13 \pm 0.02$ & $0.14 \pm 0.02$ & $0.92 \pm 0.14$ \\
$\mathrm{~Pb}$ & $0.27 \pm 0.03$ & $0.72 \pm 0.09$ & $0.47 \pm 0.06$ \\
$\mathrm{Zn}$ & $9.67 \pm 1.30$ & $5.83 \pm 0.78$ & $8.45 \pm 1.13$ \\
\hline
\end{tabular}

\section{Conclusion}

The ICP-MS method is considered to be an excellent tool for detailed characterization of elementary composition of honey samples. The analytical procedure developed for determining the mass fractions of 13 elements in honey samples turned out to be selective, linear, accurate and precise. In comparison with previous publications, this report shows for the first time results of honey trace element analysis with expanded uncertainty $U_{\text {rel }}$ for $k=2$, which range from 4.8 to $24.4 \%$. It was found that recovery (both for CRM recovery analysis and for spike samples analysis) introduces considerable uncertainty of the final measurement result for most of the mass fractions of elements, except for macroelements such as $\mathrm{Ca}, \mathrm{K}$ and $\mathrm{Mg}$. The calibration uncertainty has a considerable influence on the total uncertainty related to $\mathrm{Ca}, \mathrm{K}$ and $\mathrm{Mg}$ mass fractions. For $\mathrm{Al}, \mathrm{Ba}$ and $\mathrm{Ca}$, it is the uncertainty for digestion which strongly contributes to the total uncertainty. The presented methods of establishing traceability to the SI system are consistent and fulfilled their role as providing reliable and comprable results. Moreover, the procedure presented here can be considered as time- and cost-efficient, suitable for a routine analysis to reveal the provenience of honey.

Acknowledgments This study was supported by the Research Project of the Polish Ministry of Science and Higher Education, MNiSzW NN204 168036.

Open Access This article is distributed under the terms of the Creative Commons Attribution Noncommercial License which permits any noncommercial use, distribution, and reproduction in any medium, provided the original author(s) and source are credited. 


\section{References}

1. Madejczyk M, Baralkiewicz D (2008) Anal Chim Acta 617:11-17

2. Chudzinska M, Baralkiewicz D (2010) Food Chem Toxic 48:284-290

3. Tuzen M, Silici S, Mendil D, Soylak M (2007) Food Chem 103:325

4. Pisani A, Protano G, Riccobono F (2008) Food Chem 107:1553

5. Lachman J, Kolihova D, Miholova D, Kosata J, Titera D, Kult K (2007) Food Chem 101:973

6. Nozal Nalda MJ, Bernal Yague JL, Diego Calva JC, MartınGomez MT (2005) Anal Bioanal Chem 382:311-319

7. Caroli S, Forte G, Alessandrelli M, Cresti R, Spagnoli M, Llio SD, Pauwels J, Kramer GN (2000) J Microchem 67:227

8. Ajtony Z, Bencs L, Haraszi R, Szigeti J, Szoboszlai N (2007) Talanta 71:683

9. Silici S, Uluozlu OD, Tuzen M, Soylak M (2008) J Hazard Mater 156:612

10. Conti ME, Stripeikis J, Campanella L, Cucina D, Tudino MB (2007) J Chem Central 1:14

11. Frias I, Rubio C, Gonzalez Iglesias T, Gutierrez AJ, Gonzalez Weller D, Hardisson A (2008) Bull Environ Contam Toxicol 80:30

12. Conti ME, Botre F (2001) Environ Monit Assess 69:267

13. Caroli S, Forte G, Iamiceli AL, Galoppi B (1999) Talanta 50:327-336

14. Ioannidou MD, Zachariadis GA, Anthemidis AN, Stratis JA (2005) Talanta 65:92

15. Tuzen M, Soylak M (2005) J Food Drug Anal 13(4):343-347

16. Stankovska E, Stafilov T, Sajn R (2008) Environ Monit Assess $142: 117$
17. Fernandez Torres R, Perez Bernal JL, Bello Lopez MA, Callejon Mochon M, Jimenez Sanchez JC, Guiraum Perez A (2005) Talanta 65:686

18. PN-EN ISO/IEC 17025:2005 General requirements for the competence of testing and calibration laboratories

19. Konieczka P, Namiesnik J (2009) Quality assurance and quality control in the analytical chemical laboratory: a practical approach. CRC Press Inc-Taylor \& Francis Ltd, Boca Raton, London

20. Terrab A, Recamales AF, Gonzalez-Miret ML, Heredia FJ (2005) Food Chem 92:305-309

21. ISO (1993) Guide to the expression of uncertainty in measurement (GUM). International Organization for Standardization, Geneva; also JCGM 100:2008 online available at http://www. bipm.org/en/publications/guides/gum

22. Guevara-Riba A, Sahuquillo A, López-Sánchez JF, Rubio R (2006) Anal Bioanal Chem 385:1298-1303

23. EUROLAB Technical Report 1/2007. Measurement uncertainty revisited: Alternative approaches to uncertainty evaluation

24. EURACHEM/CITAC (2000) Quantifying uncertainty in analytical measurement, 2nd edn. LGC, Teddington

25. EURACHEM/CITAC (2007) Guide: use of uncertainty information in compliance assessment, 1st ed. www.eurachem.org/ index.php/publications/guides/uncertcompliance

26. Yenisoy-Karakas S (2007) J Chem Metrl 1(1):10-24

27. D'Ilio S, Petrucci F, D'Amato M, Di Gregorio M, Senofonte O, Violante N (2008) Anal Chim Acta 624:59-67

28. Koellensperger G, Hann S, Nurmi J, Prohaska T, Stingeder G (2003) J Anal At Spectrom 18:1047-1055

29. Salomon S, Jenne V, Hoenig M (2002) Talanta 57:157-168 